\title{
Effect of compliance to the discharge instructions among patients with internal fixation for hip fracture
}

\author{
Nagwa M. Ahmed, Sahar A. Abd-El mohsen* \\ Medical-Surgical Nursing Dept., Faculty of Nursing, Assiut University, Assiut, Egypt
}

Received: October 3, 2017

Accepted: December 3, 2017 Online Published: December 12, 2017

DOI: $10.5430 /$ jnep.v8n4p112

URL: https://doi.org/10.5430/jnep.v8n4p112

\begin{abstract}
Background and objective: Internal fixation is recommended when the need is urgent for preserving the hip joint rather than replacing it. The aim of this study was to evaluate the effect of complying with an educational intervention (booklet) and the discharge instructions on the outcomes of patients with internal fixation for hip fracture.

Methods: Research hypothesis: Strength, hip range of motion, walking ability, managing stairs, and total indoor and outdoor activities will be better among the educational intervention group than the control group. Quasi-experimental (study/control) design was utilized to conduct this research, the intervention included training patients on postoperative exercises, showing them videos on these exercises and providing them with a written simplified, photo illustrated Arabic booklet containing the discharge instructions. Setting: The study was conducted in the orthopedic department and orthopedic outpatient clinic. Sample: Consisted of 60 adult male $(63.3 \%)$ and female $(36.7 \%)$ patients who underwent internal fixation for hip fracture who were randomly included as an intervention $(n=30)$ or control group $(n=30)$. Tools: A Structured patient interview questionnaire sheet was utilized for data collection with the following three parts (biosociodemographic data, compliance behavior index and functional capability index).

Results: Of the intervention group participants (83.3\%) were compliant while nearly all of the control group subjects were non-compliant $(96.7 \%)$ at 3 months and a highly statistically significant difference was found between compliance behavior and patient's functional capability.

Conclusion: Providing structured discharge guidelines for patients who underwent internal fixation for hip fracture was effective in improving outcomes of patients than the standard hospital instructions. Recommendations: Publication of the booklet and dissemination among patients with internal fixation for hip fracture on a larger probability sample is recommended.
\end{abstract}

Key Words: Compliance, Discharge instructions, Internal fixation, Hip fracture

\section{INTRODUCTION}

Fractures of the hip are associated with high rates of mortality; among elderly patients hip fractures are responsible for $7 \%-14 \%$ mortality rate. ${ }^{[1,2]}$ Hip fracture is a sudden traumatic event, threatening many aspects of patient's life as a result of the effects of functional disability. The reduced mobility often causes increased dependence on others. Restricted mobility has an impact on everyday activities, which affects the patient's emotional state and results in a loss of confidence. This puts patients at higher risk of becoming permanently disabled and dependent, even after a successful operation. ${ }^{[3]}$ Mobility problems and impaired physical function may affect mental well-being after a hip fracture and lead to reduced ability to participate in social activities. This may result in long-lasting consequences for about a year following the fracture. ${ }^{[4]}$

\footnotetext{
${ }^{*}$ Correspondence: Sahar A. Abd-El mohsen; Email: sara.saleh17@ yahoo.com; Address: Medical-Surgical Nursing Dept., Faculty of Nursing, Assiut University, Assiut, Egypt.
} 
The time of discharge from the hospital is the transition point at which patients go from a protective and familiar environment, where the caregivers are responsible for their needs, to the home environment where they and their families become the primary caregivers. In many cases, patients are unable to stand or walk independently. So the role and responsibility of the patient's family cannot be overemphasized. ${ }^{[5,6]}$

Operative goals for patients with internal fixation for hip fracture are: restoration of anatomical alignment, stable fixation, achieving high union rates, minimizing blood loss, shortening operative time and early weight bearing. ${ }^{\text {[7] Surgical }}$ interventions for hip fracture such as internal fixation and total hip replacement can lead to many complications (e.g. deep vein thrombosis, and pneumonia) and may affect about $20 \%$ of patients with hip fracture. ${ }^{[8]}$ Cognitive and neurological alterations, venous thromboembolism, gastrointestinal tract (GIT) bleeding, urinary tract complications, electrolyte and metabolic disorders, and pressure ulcers are the most important complications after hip surgery. ${ }^{[9,10]}$

Effective patient education at discharge represents a great challenge for patients and their families, and leads to success of surgery which will increase patient's level of functioning and their quality of life largely however it depends on their compliance to the discharge instructions provided. ${ }^{[11]}$

In a university hospital, the monthly admission rate for hip fracture was about 60 patients out of 250 , of those patients about two thirds were having trochanteric hip fracture and many of those patients returned to the outpatient orthopaedic clinic with complications that could be avoided if the patient complied with the discharge instructions.

The aim of this study was to evaluate the effect of complying with an educational intervention (booklet) and the discharge instructions on the outcomes of patients with internal fixation for hip fracture.

\section{Research hypothesis}

Strength, hip range of motion, walking ability, managing stairs, and total indoor and outdoor activities will be better among the educational intervention group than the control group.

\section{Patients And method}

\subsection{Research design}

Quasi-experimental (study/control) research design was utilized.

\subsection{Setting}

The study was conducted in an orthopedic department and orthopedic outpatient clinic of a University Hospital in (Egypt).

\subsection{Patients}

A total of 60 adult male and female patients who underwent internal fixation for hip fracture were included. Patients were randomly assigned into two groups: group I $(n=30)$ which was the "intervention" group and group II $(\mathrm{n}=30)$ which was the control group. Group "I" participants received an educational booklet containing the discharge instructions and were trained on the exercises contained in it, while group "II" received the standard hospital care (the standard hospital care included only oral instructions on discharge by the resident surgeon).

\subsection{Inclusion criteria}

Any type of hip fracture regardless of the cause, both gender and age range between 18 to 65 years.

\subsection{Exclusion criteria}

Mentally ill patients, or patients unable to read, comprehend or understand the instructions, hearing or visual difficulties, compound fractures, concomitant surgeries (e.g. back or knee surgery), rheumatoid arthritis of the hip.

The randomization was performed by including the patients admitted on Saturdays, Mondays and Tuesdays in the intervention group and the patients admitted during the rest of the week days in the control group.

\subsection{Tool}

\subsubsection{Patient interview questionnaire sheet}

This was structured by the researchers and it contained three parts:

First part: Biosociodemographic data of the patients (age, gender, marital status, education and occupation).

Second part: Compliance behavior index: This is an observation checklist, which consisted of 6 items used to observe patient's ability to perform these activities: sitting, standing, getting in and out of bed "postoperatively". These items were scored as performed (1) or not performed (0).

The total maximum score for all items was 6 . Those who obtained less than 4 were considered as having non-compliant behavior, while patients obtained from 4-6 were considered as having compliant behavior.

Third part: Functional capability index: It included items for assessing the following: strength, total range of motion (ROM), walking ability, managing stairs, total indoor activities, total outdoor activities, and total activities of daily living (i.e. feeding, showering, getting dressed, and toileting).

\subsubsection{Discharge Instructions booklet}

The educational booklet was written in simple Arabic language by the researchers and it was supported by illustrated 
pictures of the needed exercises, and videos explaining how to perform each of these exercises (deep breathing and coughing exercises, proper positioning in bed postoperatively, postoperative exercises, warning signs and symptoms of complications that might occur, instructions on selected activities of daily livings [as mentioned before] and safe methods of performing these activities, and the proper and safe use of the prescribed walking aid), the researchers trained each patient in the educational (intervention group), and those patients were given a copy of the booklet to take home on discharge, this booklet was revised by a jury of five experts for clarity, easiness and relevance ( 2 orthopedic surgeons, two medicalsurgical nursing faculty staff and one physiotherapist), after making the necessary modifications; the booklet was pilot tested on 6 patients to ensure easiness and clarity for understanding.

\subsection{Procedure}

\subsubsection{Preparatory phase}

During this phase the researchers conducted the assessment process for the number of cases admitted in the orthopedic department for performing internal fixation for hip fracture. The research was approved from faculty of nursing - ethics committee. Official permission was obtained from the head of orthopedic department and out-patient clinics to collect the necessary data. Collecting the review materials and preparing the tools for data collection from library and internet sources. The discharge instruction booklet was prepared in simple Arabic language with simple photo illustrations (this was revised by 5 health professionals as mentioned earlier). A pilot study was done during June 2016 on 6 patients to examine clarity and applicability of the tool, no changes were done in the tools, and only minor modifications were done in the booklet for simplification of the instructions. So that patients in the pilot study were excluded from the main study.

\subsubsection{Implementation phase}

Random allocation of patients into two groups (intervention or control) with each comprising 30 patients. Patients from both groups were interviewed individually for filling the study tools on admission. The intervention group was given the pre-discharge instructions from the researchers and was given a copy from the discharge instructions booklet, while the control group was given the standard hospital instructions. Patients in the intervention group were met for three sessions; one preoperatively for training on the basic postoperative care (deep breathing and coughing exercises) and the other two sessions postoperatively. The second postoperative session involved training on exercises by the researcher (nursing staff) herself and through showing patients video demonstrating these exercises. The exercises during 114 the 1 st week involved a full range active movements of the ankle, gentle active movements of flexion and extension of the hip and knee (once the pain subsides), and no passive range of motion. After the pain subsides, isometric gluteal and quadriceps exercises are begun. Isotonic exercises are prescribed for the ankle as it helps to strengthen the gastrosoleus muscle and reduces the chances of thrombophlebitis and deep vein thrombosis. Use of raised toilet seat and chair, wearing the trousers from the affected limb first and removing it from the unaffected limb, rolling on to the unaffected side before getting up from the bed are some of the recommended modifications in daily living, use of other person to perform heavy activities as cleaning or cooking which needs long time of standing. The third postoperative session included information and demonstration on the use of the walking aid prescribed for the patient and on the importance of follow up, where to follow up their visits, warning signs and symptoms to report.

\subsubsection{Evaluation phase}

Patients from both groups were interviewed individually for assessment in the out-patient orthopaedic clinic using the pre-mentioned study tools 3 months after the operation.

\subsection{Ethical considerations}

The research was approved by the ethics committee in faculty of nursing, a written consent was obtained from patients participating in the work after explaining the nature and purpose of the study. Patients were assured data confidentiality, and the researchers initially introduced themselves to the study subjects and patients were informed that their participation is voluntary and they can withdraw any time from the work.

\subsection{Statistical analysis}

Data entry and statistical analysis were done using SPSS ver. 23 statistical software packages. Data were presented using descriptive statistics in the form of frequencies and percentages for qualitative variables, mean and standard deviations for the quantitative variables. The level of significance was set at $(p=.05)$ to detect any indication of differences found in the data available.

\section{RESULTS}

Table 1 shows that there was no statistically significant difference between both groups regarding their biosociodemographic characteristics and more than half of patients in group I $(53.3 \%)$ and the majority in group II $(73.3 \%)$ were male, an equal percent in both groups $(66.7 \%)$ were married, the greater percent $(38.4 \%)$ their age was between 30 to less than 45 years, $(75 \%)$ were secondary educated and $(55 \%)$ were working in both groups. 
Table 1. Distribution of personal characteristics of the studied patients $(n=60)$

\begin{tabular}{|c|c|c|c|c|c|}
\hline \multirow{2}{*}{ Variable } & \multicolumn{2}{|c|}{ Group I (intervention) $(\mathrm{n}=\mathbf{3 0})$} & \multicolumn{2}{|c|}{ Group II (control) $(n=30)$} & \multirow{2}{*}{$p$-value } \\
\hline & N. & $\%$ & N. & $\%$ & \\
\hline Sex & & & & & .11 \\
\hline Male & 16 & 53.3 & 22 & 73.3 & \\
\hline Female & 14 & 46.7 & 8 & 26.7 & \\
\hline \multicolumn{6}{|l|}{ Marital status } \\
\hline Married & 20 & 66.7 & 20 & 66.7 & 1.00 \\
\hline Not-married & 10 & 33.3 & 10 & 33.3 & \\
\hline Age & & & & & .86 \\
\hline $18-<30$ years & 9 & 30 & 11 & 36.7 & \\
\hline $30-<45$ years & 12 & 40 & 11 & 36.7 & \\
\hline 45 and above & 9 & 30 & 8 & 26.6 & \\
\hline \multicolumn{6}{|l|}{ Educational level } \\
\hline Illiterate & 9 & 30 & 6 & 20.0 & .37 \\
\hline Educated & 21 & 70 & 24 & 80 & \\
\hline \multicolumn{6}{|l|}{ Occupation } \\
\hline Not working & 11 & 36.7 & 7 & 23.3 & .26 \\
\hline Working & 19 & 33.3 & 23 & 76.7 & \\
\hline
\end{tabular}

Table 2 shows a highly statistically significant difference between both groups regarding their compliance behavior. Of group I participants $83.3 \%$ were compliant while nearly all of group II subjects were non-compliant $96.7 \%$ at 3 months.

Table 3 shows that there was no statistically significant rela- tion between compliance behavior and biosociodemographic characteristics of the studied sample.

Table 4 shows that there was a highly statistically significant difference between compliance behavior and patient's functional capability in the studied patients.

Table 2. Compliance behavior index for hip internal fixation patients in both groups $(\mathrm{n}=60)$

\begin{tabular}{|c|c|c|c|c|c|}
\hline \multirow{2}{*}{ Variable } & \multicolumn{2}{|c|}{ Group I $(n=30)$} & \multicolumn{2}{|c|}{ Group II $(n=30)$} & \multirow{2}{*}{$p$-value } \\
\hline & N. & $\%$ & $\mathbf{N}$. & $\%$ & \\
\hline \multicolumn{6}{|l|}{ Compliance index: (as observed by the researcher) } \\
\hline Hip flexion not more than $90^{\circ}$ when sitting & 27 & 90 & 18 & 60 & $.007 *$ \\
\hline Not crossing legs when sitting & 26 & 86.7 & 11 & 36.7 & $.001^{*}$ \\
\hline Operated leg kept straight when getting up & 26 & 86.7 & 13 & 43.3 & $.001 *$ \\
\hline Push self-up using arms of chair & 25 & 83.3 & 11 & 36.7 & $.001^{*}$ \\
\hline Operated leg kept straight when getting out of bed & 24 & 80 & 9 & 30 & $.001 *$ \\
\hline Push self-up from bed using arms & 25 & 83.3 & 12 & 40 & $.001^{*}$ \\
\hline \multicolumn{6}{|l|}{ Total compliance } \\
\hline Compliant (4-6) & 25 & 83.3 & 1 & 3.3 & \multirow{2}{*}{$.001 *$} \\
\hline Non-compliant $(<4)$ & 5 & 16.7 & 29 & 96.7 & \\
\hline
\end{tabular}

\section{Discussion}

The current research included 60 adult male and female patients, the greatest percent in both groups were male, married, their age was between 30 to less than 45 years, and this actually agrees with our Egyptian community in which our youth in this age group uses the motor cycles which is responsible Published by Sciedu Press for most of accidents and even deaths in our community.

This study result agree with the study conducted at a traumatology department by Ismael et al. (2016) ${ }^{[12]}$ who found that most of the admitted patients their age ranged from more than thirty to less than forty years. 
Table 3. Relation between patient's compliance and their biosociodemographic characteristics post hip internal fixation

\begin{tabular}{|c|c|c|c|c|c|}
\hline \multirow{3}{*}{ Variable } & \multicolumn{4}{|c|}{ Compliance in both groups (intervention and control) } & \multirow{3}{*}{$p$-value } \\
\hline & \multicolumn{2}{|c|}{ Compliant $(\geq 60 \%)$} & \multicolumn{2}{|c|}{ Non-Compliant $(<60 \%)$} & \\
\hline & $\mathbf{N}$. & $\%$ & $\mathbf{N}$. & $\%$ & \\
\hline \multicolumn{6}{|l|}{ Sex } \\
\hline Male & 15 & 57.7 & 23 & 67.7 & \multirow[t]{2}{*}{.43} \\
\hline Female & 11 & 42.3 & 11 & 32.4 & \\
\hline \multicolumn{6}{|l|}{ Marital status } \\
\hline Married & 18 & 69.2 & 22 & 64.7 & \multirow[t]{2}{*}{.71} \\
\hline Not-married & 8 & 30.8 & 12 & 35.3 & \\
\hline \multicolumn{6}{|l|}{ Age } \\
\hline $18-<30$ years & 9 & 34.6 & 11 & 32.4 & \multirow{3}{*}{.72} \\
\hline $30-<45$ years & 11 & 42.3 & 12 & 35.3 & \\
\hline 45 and above & 6 & 23.1 & 11 & 32.4 & \\
\hline \multicolumn{6}{|l|}{ Educational level } \\
\hline Illiterate & 6 & 23.1 & 9 & 26.5 & \multirow[t]{2}{*}{.76} \\
\hline Educated & 20 & 76.9 & 25 & 73.5 & \\
\hline \multicolumn{6}{|l|}{ Occupation } \\
\hline Not working & 9 & 34.6 & 9 & 26.5 & \multirow{2}{*}{.50} \\
\hline Working & 17 & 65.4 & 25 & 73.5 & \\
\hline
\end{tabular}

Table 4. Relation between patient's compliance and their functional capability post hip internal fixation

\begin{tabular}{|c|c|c|c|c|c|}
\hline \multirow{3}{*}{ Variable } & \multicolumn{4}{|c|}{ Compliance in both groups (intervention and control) } & \multirow{3}{*}{$p$-value } \\
\hline & \multicolumn{2}{|c|}{ Compliant $(\geq 60 \%+)$} & \multicolumn{2}{|c|}{ Non-Compliant $(<60 \%)$} & \\
\hline & N. & $\%$ & N. & $\%$ & \\
\hline \multicolumn{6}{|l|}{ Strength } \\
\hline Severe weakness $(0-2)$ & 9 & 34.6 & 32 & 94.1 & $.001 *$ \\
\hline Moderate - mild weakness (3-5) & 17 & 65.4 & 2 & 5.9 & \\
\hline \multicolumn{6}{|l|}{ Total ROM } \\
\hline Good $(50 \%+)$ & 25 & 96.2 & 10 & 29.4 & $.001 *$ \\
\hline Poor $(<50 \%)$ & 1 & 3.8 & 24 & 70.6 & \\
\hline \multicolumn{6}{|l|}{ Walking ability } \\
\hline With cane or crutch (1-4) & 18 & 69.2 & 34 & 100.0 & $.001 *$ \\
\hline Without (5-6) & 8 & 30.8 & 0 & 0.0 & \\
\hline \multicolumn{6}{|l|}{ Managing stairs } \\
\hline Unable - with difficulty (0-2) & 7 & 26.9 & 32 & 94.1 & $.001 *$ \\
\hline Without difficulty (3-6) & 19 & 73.1 & 2 & 5.9 & \\
\hline \multicolumn{6}{|l|}{ Total indoor activities } \\
\hline Dependent (0-2) & 12 & 46.2 & 32 & 94.1 & $.001 *$ \\
\hline Independent (3-4) & 14 & 53.8 & 2 & 5.9 & \\
\hline \multicolumn{6}{|l|}{ Total outdoor activities } \\
\hline Dependent $(0-2)$ & 8 & 30.8 & 30 & 88.2 & $.001 *$ \\
\hline Independent (3-4) & 18 & 69.2 & 4 & 11.8 & \\
\hline \multicolumn{6}{|l|}{ Total activities of daily living } \\
\hline Dependent (0-2) & 12 & 46.2 & 32 & 94.1 & $.001 *$ \\
\hline Independent (3-4) & 14 & 53.8 & 2 & 5.9 & \\
\hline
\end{tabular}


The present study found that patients in the intervention group who received the written discharge instructions were having better outcomes compared to those who received the standard pre-discharge instructions; this is supported by Anthony et al. (2004) ${ }^{[13]}$ who advocated the need for structured patient education based on individualized patient needs. Also Awad et al. (2006) and Beaupre et al. $(2013)^{[14,15]}$ pointed out to the importance of the written discharge instructions when they said that verbal instructions are partially effective and are sometimes forgotten or ignored by some of the patients.

Our study demonstrated that the activity of daily livings was greatly better among patients who were compliant to the discharge instructions than those who were not compliant; this result was inline with the study conducted by Ben-Morderchai et al. ${ }^{[1]]}$ who found that the activity of daily livings items was better among group 1 patients compared to the control group.

Our study also revealed a highly statistically significant difference between both groups, and between patient's compliance behavior and their functional capabilities. Also there was no significant relation between patient's compliance behavior and their biosociodemographic characteristics. This result

\section{REFERENCES}

[1] Parker M, Magnusson C. Assessment of trauma patients. International Journal of Orthopaedic and Trauma Nursing. 2015; 21: 21-30. PMid:26655681 https://doi.org/10.1016/j.ijotn.2015.1 0.002

[2] Cooper C, Campion G, Melton LJ. Hip fractures in the elderly: A worldwide projection. Osteoporosis Int. 1992; 2: 285-89. https: //doi.org/10.1007/BF01623184

[3] Pasco JA, Sanders KM, Hoekstra FM, et al. The human cost of fracture. Osteoporos. Int. 2005. https ://doi.org/10.1007/s00198 -005-1997-y

[4] Zidoen L, Scherman MH, Wenestam CG. The break remains - elderly peoples' experiences of a hip fracture 1 year after discharge. Disabil. Rehabil. 2010. https ://doi.org/10.3109/096382809030 09263

[5] DiGioia A, Greenhouse PK, Levison TJ. Patient and family-centered collaborative care: an orthopaedic model. Clinical Orthopaedics and Related Research. 2007; 463: 13-19. PMid:17960670

[6] Klein FM, Burda ML, Epstein BA, et al. Collaborating to enhance patient education and recovery. Journal Library Association. 2005.

[7] Petsatodis G, Maliogas G, Karikis J. External fixation for stable and unstable inter-trochanteric fractures, a prospective comparative study. J Orthop Trauma. 2011.

[8] Roche JJ, Wenn RT, Sahota O, et al. Effect of comorbidities and postoperative complications on mortality after hip fracture in elderly people: prospective observational cohort study. BMJ. 2005; 331: comes in accordance with a study which was conducted by Ben-Morderchai et al. ${ }^{[11]}$ in their study in which they concluded that orthopedic patients who received the structured education at the time of discharge had improved outcomes six weeks after discharge compared to those patients who received the standard information.

\section{Limitations of the study}

The study only included 60 patients (a small sample size) as many patients were having concomitant fractures or were illiterate so they were excluded from the study.

\section{Conclusion}

Providing structured discharge guidelines for patients who underwent internal fixation for hip fracture was effective in improving outcomes of patients than the standard hospital instructions.

\section{Recommendations}

Publication of the booklet and dissemination among patients with internal fixation for hip fracture on a larger probability sample is recommended.

\section{CONFlicts of InTEREST Disclosure}

The authors declare that there is no conflict of interest.
1374. PMid:16299013 https://doi .org/10.1136/bmj . 38643. 663843.55

[9] Chong CP, Savige JA, Lim WK. Medical problems in hip fracture patients. Arch Orthop Trauma Surg. 2010. PMid:20049603 https://doi.org/10.1007/s00402-009-1038-y

[10] Monte-Secades R, Peña-Zemsch M, Rabuñal-Rey R, et al. Risk factors for the development of medical complications in patients with hip fracture. Rev Calid Asist. 2011. PMid:21339079 https : //doi.org/10.1016/j.cali.2010.09.003

[11] Ben-Morderchai B, Herman A, Kerzman H, et al. Structured discharge education improves early outcome in orthopedic patients. International Journal of Orthopedic and Trauma Nursing. 2010. https://doi.org/10.1016/j.joon.2009.02.001

[12] Ismael MA, Muhammad ZA, Abd El-mohsen SA, et al. Prevalence and Predisposing Factors of Compartment Syndrome among Patients with Lower Limb Fracture at Assiut University Hospital, Master thesis. 2016.

[13] Anthony MK, Hudson-Barr D. A patient centered model of care for hospital discharge. Clinical Nursing Research. 2004. PMid:15104855 https://doi.org/10.1177/1054773804263165

[14] Awad IT, Chung F. Factors affecting recovery and discharge following ambulatory surgery. Canadian Journal of Anesthesia. 2006 PMid:16960263 https://doi.org/10.1007/BF03022828

[15] Beaupre LA, Binder EF, Cameron ID, et al. Maximising functional recovery following hip fracture in frail seniors. Best Pract. Res. Clin. Rheumatol. 2013. http://dx.doi.org/10.1016/j.berh. 2014 .01 .001 